\title{
ANÁLISE DA FRAGILIDADE AMBIENTAL A PARTIR DE PROCESSOS EROSIVOS NA SUB-BACIA DO CÓRREGO PERAPUTANGA, RESERVA DO CABAÇAL-MT
}

\author{
Ana Rosa Ferreira ${ }^{(a)}$, José Eriston Nonato Santana ${ }^{(b)}$ \\ (a) Departamento de Geografia, Faculdade de Ciências Humanas, Universidade do Estado de Mato Grosso - \\ ferreiraar2004@hotmail.com \\ (b) Graduando do Departamento de Geografia, Faculdade de Ciências Humanas, Universidade do Estado de Mato \\ Grosso - nonatosantana@ hotmail.com
}

\section{Eixo: GEOGRAFIA FÍSICA E DESASTRES NATURAIS}

\begin{abstract}
Resumo
A erosão do solo é um processo de trabalho no sentido físico, que envolve consumo de energia em todas as fases da erosão: no rompimento do solo, no salpicamento das partículas, na turbulência do escoamento superficial e transporte das partículas de solo. Este trabalho consiste na análise da fragilidade ambiental na bacia do córrego Peraputanga, em Reserva do Cabaçal, a partir do estudo de voçorocas presentes na região. Para o seu desenvolvimento, realizou-se a revisão teórica bibliográfica sobre o tema estudado, bem como analisou as condições físico-químicas e mineralógicas do solo, ocorrência ou ausência de vegetação nativa e influência das condições climáticas regionais e os aspectos geomorfológicos. Durante os trabalhos de campo, foram mensurados a profundidade, largura e comprimento das voçorocas durante a estação seca e chuvosa, buscando identificar o período de maior crescimento das erosões. Os dados coletados permitiram a análise dos elementos que compõem a fragilidade ambiental da região e de que maneira estão alterando a paisagem natural. Os solos apresentam grande fragilidade devido sua composição mineralógica associado aos fatores de declividade, desmatamentos e construção de estradas sem planejamento.
\end{abstract}

Palavras-Chave: erosão; fragilidade ambiental desmatamento

\section{1 - INTRODUÇÃO}

No Brasil, um dos fatores de desgaste que mais contribui para a erosão do solo são erosões hídricas, facilitadas e aceleradas pelas atividades antrópicas e suas práticas inadequadas de manejo, tais como: plantio continuado e mal distribuído de culturas esgotantes e pouco protetoras do solo; plantio em linhas a favor das águas; queimada drástica dos restos culturais e o pastoreio excessivo de bovinos.

Vários são os fatores que combinados contribuem para o desencadeamento dos processos erosivos, condicionantes como o desmatamento sem controle da vegetação para fins exclusivamente econômicos visando lucros imediatos. O uso e manejo do solo de maneira incorreta ou irregular, sem considerar o seu potencial, ultrapassando seus limites de produção e ainda, não fazendo a correção com nutrientes e matéria orgânica que o solo necessita para se manter estável, tornando-o vulnerável diante da dinâmica dos processos erosivos. (CUNHA e GUERRA 2002).

A erosão é um processo de deslocamento de terra ou de rochas de uma superfície, pode ocorrer por ação de fenômenos da natureza ou do ser humano. No que se refere às ações da natureza, podemos 
citar as chuvas como principal causadora da erosão. Ao atingir o solo, em grande quantidade, provoca deslizamentos, infiltrações e mudanças na consistência do terreno. Desta forma, provoca o deslocamento de terra. $\mathrm{O}$ vento e a mudança de temperatura também são causadores importantes da erosão. (CASSETI 1991).

As atividades antrópicas são importantes agentes provocadores das erosões. Ao retirar a cobertura vegetal de um solo, este perde sua consistência, pois a água, que antes era absorvida pelas raízes das árvores e plantas, passa a infiltrar pouco no solo. Esta pouca infiltração e escoamento superficial podem causar a instabilidade do solo e a erosão. (GUERRA e JORGE 2013).

O município de Reserva do Cabaçal apresenta problemas de voçorocamentos que estão causando não só impactos ambientais como socioeconômicos, dessa forma, é necessário o estudo das causas e das consequências das erosões, implicando em levantamentos da evolução espaço-temporal do processo erosivo, bem como o que está acelerando este processo, assim como, o que pode ser feito para recuperar as áreas degradadas e evitar o surgimento de novos pontos de ravinamentos e voçorocas.

Este trabalho consiste na análise da fragilidade ambiental na bacia do córrego Peraputanga, em Reserva do Cabaçal, a partir do estudo de voçorocas presentes na região. Para o seu desenvolvimento analisou as condições físico-químicas e mineralógicas do solo, bem como a presença ou ausência de vegetação nativa e influência das condições climáticas regionais.

\section{2 - FUNDAMENTAÇÃO TEÓRICA}

Segundo Guerra e Jorge (2013) a erosão dos solos não é apenas um problema para as áreas em que ocorre, ao diminuir a quantidade de nutrientes no topo do solo, mas também causa assoreamento em que os sedimentos se depositam em especial, quando se trata de reservatórios, rios, lagos e açudes. Os problemas relativos à erosão ocorrem quando as taxas de perda de solo ultrapassam níveis naturais, geralmente por falta de práticas conservacionistas.

Conforme Guerra e Jorge (op. Cit.), os problemas resultantes da erosão dos solos podem ser exemplificados da seguinte forma: remoção dos nutrientes existentes no topo dos solos; redução da penetração nas raízes e do armazenamento de água; a diminuição das áreas a serem utilizadas para a agricultura e pecuária; aumento do assoreamento de rios, lagos, reservatórios e açudes, levando muitas vezes a grandes enchentes em várias partes do mundo; poluição dos corpos líquidos, em especial pelo transporte de defensivos agrícolas, junto com os sedimentos erodidos.

As principais causas de erosão, de acordo com Wild (1993) são: 1. Desmatamento, deixando os solos desprotegidos; 2. Agricultura e pecuária, deixando os solos desprotegidos; 3. Cultivo e pecuária em encostas de elevada declividade, às vezes superior a $45^{\circ}$, sem adoção de práticas conservacionistas; 4. Trilhas abertas por animais e homens, compactando os solos, por onde a água se escoa com facilidade; 
5. Construção de rodovias sem cuidados especiais, o que faz aumentar o escoamento superficial, causando ravinas que podem evoluir para voçorocas; 6. Mineração e outras atividades econômicas, que deixam os solos desprotegidos, sem recuperação dessas áreas, durante e após o termino das atividades.

Nir (1983) propõe a análise de cada uma das modalidades de intervenções antrópicas na paisagem, invertendo, o raciocínio dos efeitos das ações antrópicas nesse processo, considerando-se a própria dinâmica de intervenção detalhando-se modalidades de manejo agrícola, edificações e construção de sistema viário, dentre outras.

Podem ser citados os movimentos de massa, corridas e enxurradas, problemas como degradação e esgotamento de recursos hídricos, inundações, contaminação do solo por disposição de recursos hídricos, inundações, contaminação do solo por disposição de rejeitos, aumento das taxas de erosão e de assoreamento, recalques, colapsos de solo etc. (GUERRA e JORGE, 2013).

Todos esses problemas, além de afetarem a qualidade de vida de parcelas da população, acabam se refletindo na economia regional, consumindo recursos vultosos na busca de soluções paliativas (MOROZ, 2010).

Cristo (2002) evidencia que os eventos naturais não correspondem necessariamente aos riscos naturais, uma vez que tais eventos se tornam riscos com a utilização do ambiente por parte do ser humano de forma inadequada ou negligente, ou seja, as áreas de riscos estão associadas à presença de ocupação humana em áreas passiveis de serem atingidas por eventos naturais.

A fragilidade dos ambientes naturais deve ser avaliada quando se pretende aplicar ao planejamento territorial e ambiental. Baseando-se no conceito de Unidades Ecodinâmicas preconizadas por Tricart (1977) uma concepção ecológica, na qual o ambiente é analisado sobre o prisma da Teoria dos Sistemas que parte do pressuposto de que na natureza as trocas de energia e matéria se processam por meio das relações de equilíbrio dinâmico.

Esse equilíbrio, entretanto, em algumas regiões pode ser alterado pelas intervenções do homem nos diversos componentes da natureza, gerando desequilíbrios temporários ou até permanentes. Diante disso Tricart (op. cit.) definiu que os ambientes, quando estão em equilíbrio dinâmico são estáveis, quando em desequilíbrio são instáveis.

Devido ao aprimoramento conceitual com relação às definições das Unidades Ecodinâmicas, Ross (1994) passou a considerar a potencialidade dos ambientes naturais e antropizados como definidora das fragilidades ambientais, não ocorrendo a separação em Emergente e potencial. Levando-se em consideração que por mais estavel que esteja um ambiente sempre está sendo indiretamente afetado pela ação antrópica, seja pela poluição do ar, seja pelas águas subterrâneas, entre outros. 


$\begin{aligned} & \text { XVII Simpósio Brasileiro } \\ & \text { de Geografia Fisica Aplicada }\end{aligned}$
$\begin{aligned} & \text { ICongresso Nacional } \\ & \text { de Geografia Física }\end{aligned}$

De acordo com Ross (1994), O mapeamento geomorfológico inicial subsidia a elaboração da carta de fragilidade ambiental, integrando os aspectos geomorfológicos com o substrato rochoso e os tipos de solos. Esses aspectos, são componentes essenciais da carta geomorfológica e, vão definir a fragilidade dos elementos que sustentam os usos e coberturas em determinados ambientes. Assim, segundo o autor, pode-se evitar a implantação de ocupações em áreas onde o relevo apresenta declividades acentuadas, ou em um solo muito raso e ainda, como é o caso de intervales, evitar usos intensivos sobre substratos rochosos de calcário.

\section{3 - PROCEDIMENTOS METODOLÓGICOS}

\subsection{Caracterização da área de estudo}

A sub-bacia do córrego Peraputanga, localiza-se no município de Reserva do Cabaçal e pertence à bacia hidrográfica do rio Cabaçal, com aproximadamente $886,49 \mathrm{~km}^{2}$ de área de influência (AVELINO, 2006), envolvendo dez municípios, a saber: Reserva do Cabaçal, Salto do Céu, Rio Branco, Lambari D’Oeste, Curvelândia, Araputanga, São José dos Quatro Marcos, Mirassol D’Oeste, Tangará da Serra e Cáceres. (Figura 1).
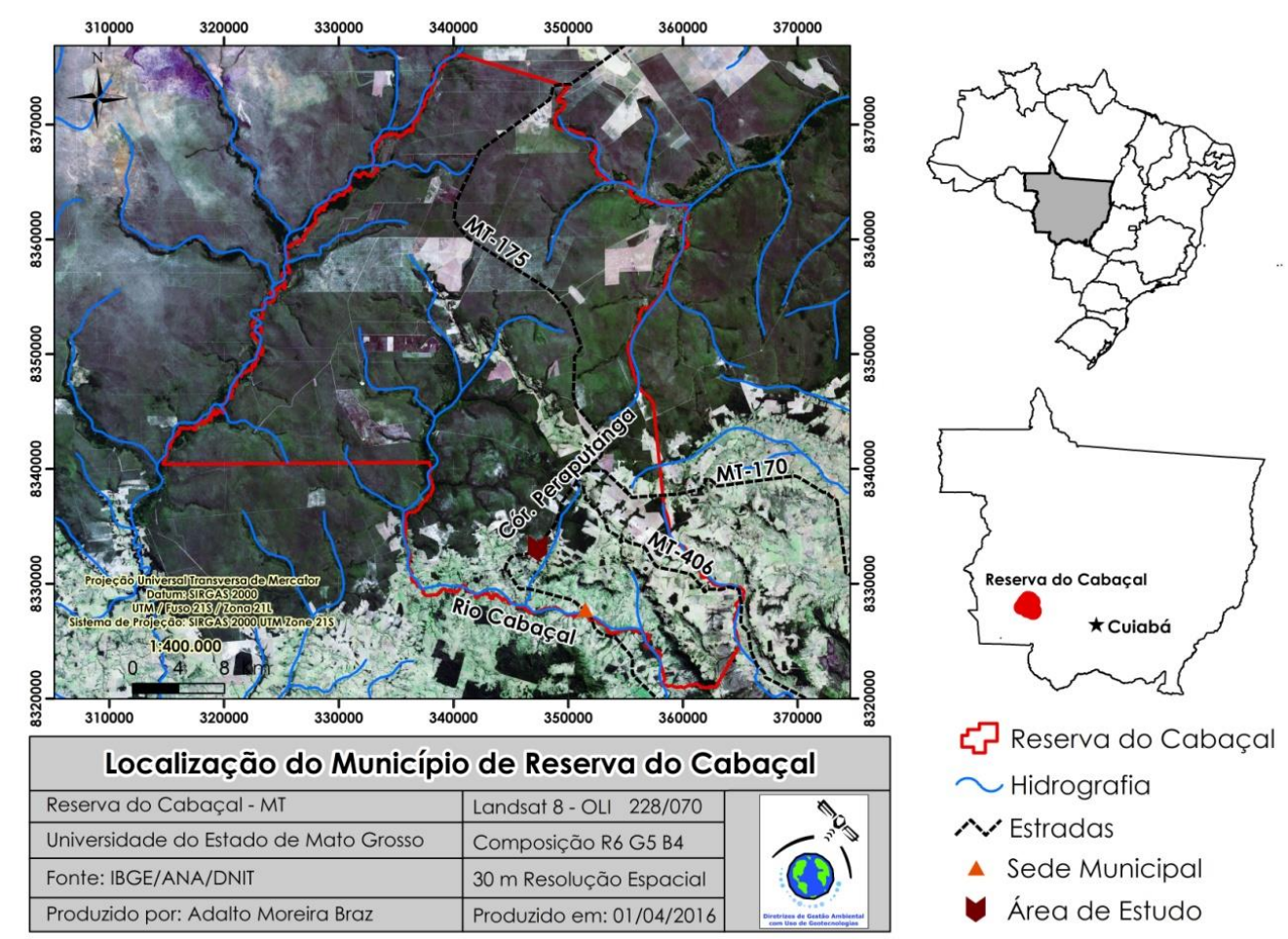

Figura 1: Mapa de localização do córrego Peraputanga - Reserva do Cabaçal-MT.

\subsubsection{Aspectos Geológicos}


De acordo com RADAMBRASIL (1982), a sub-bacia do córrego Peraputanga compõe os córregos e rios que formam a grande bacia hidrográfica do rio Cabaçal, apresentando diferentes formações geológicas datadas do Pré-Cambriano Inferior (Complexo Xingu), Pré-Cambriano Superior ao Cenozóico (Grupo Alto Paraguai), Mesozóico-Cretáceo/Terciário (Grupo Parecis) e Quaternário (Aluviões Atuais e Antigos).

Conforme registros científicos do projeto RADAMBRASIL (1982); Barro et al. (1982); Bittenocurt Rosa et al. (1994) a bacia hidrográfica do rio Cabaçal é composta pelas seguintes formações:

\subsubsection{Grupo Aguapeí}

Almeida et al. (1971) e Figueiredo et al. (1974) denominaram esses tipos de rocha de formação Aguapeí, a qual dividiu em três subunidades: inferior, constituída por metaconglomerados digomítico com intercalação de metarenitos; média, formada por ardósias, filitos e metasilititos; e, superior, constituída de metarenitos feldispáticos. Sua posição estratigráfica ocorre sobreposta às rochas do complexo Xingu e cortadas pelas rochas que constituem este grupo que possuem contatos transacionais.

Esta unidade, segundo estudos realizados pelo RADAMBRASIL (1982), teve inicio em meados do Pré-Cambriano Superior, visto que diques de diabásio que atravessam algumas de suas rochas apresentaram idades em torno de 1.500 MA.

Para Souza e Hildrede (1980) o Grupo Aguapei constitui uma cobertura de plataforma, cujos metassedimentos estariam ligados a uma sequencia marinha transgressiva-regressiva sobre um embasamento aplanado. Baseados na legislação contida no Código de Nomenclatura Estratigráfica propuseram a elevação da unidade Aguapeí para Grupo, separando este grupo em três formações, isto é, Fortuna, Vale da Promissão e Morro Cristalino.

\subsubsection{Aspectos Geomorfológicos}

De acordo com RADAMBRASIL (1982) a bacia hidrográfica do rio Cabaçal foi classificada em três unidades geomorfológicas: Planalto dos Parecis, Depressão do Alto Paraguai e Província Serrana. Apresenta variações marcantes nos aspectos geomorfológicos, tais como a região de superfície dissecada, a depressão de rebaixamento (Depressão do Alto Paraguai) e a superfície de acumulação caracterizada como planície de inundação (Sedimentar).

O relevo da área de estudo em questão foi reconhecido na unidade geomorfológica do Planalto dos Parecis, que se subdivide em diversas formas erosivas: a) superfície pediplana - aplanamento elaborado por processo de pediplanação, cortando litologias pré-cambrianas do complexo basal, grupo Cuiabá, grupo Alto Paraguai e terciários do Planalto dos Parecis; b) superfície erosiva tabular - relevo 
residual de topo aplainado provavelmente testemunha de superfície aplainada, geralmente limitada por escarpas erosivas; c) superfície estrutural tabular - aplainamento de topo parcial ou totalmente coincidente com a estrutura geológica, limitada por escarpas e retrabalhada por processos de pediplanação (SEPLAN, 2011).

\subsubsection{Aspectos Pedológicos}

A região de abrangência da bacia Hidrográfica do Cabaçal por sua extensão apresenta grande variabilidade de classe de solo, estando representada pelos seguintes tipos de solo: Latossolos, Neossolos Litólicos, Cambissolos, Organossolos, Argissolos e Neossolos Quatzarênicos (AVELINO, 2006).

Para Salomão (1994), nessa área, há a existência de diferentes sistemas pedológicos: com diferenciações lateral e vertical, que se repetem sistematicamente na paisagem, sendo coberturas pedológicas entendidas como os elementos fundamentais de distinção dos sistemas pedológicos. Estes sistemas se constituem de horizontes com determinada distribuição espacial na vertente, apresentando compartimentos hídricos específicos, constituindo sequências com evidentes significados genéticos, permitindo caracterizar interflúvios elementares de mesma família, de acordo com o estado de evolução, sendo possível cartografá-los de maneira sistemática.

De acordo com Secretaria de Planejamento - SEPLAN (2011) predominam os neossolos quartzarênicos álicos. Nesta classe, estão agrupados solos profundos e muito profundos, de pouco desenvolvimento, com as seqüências de horizontes do tipo A/C. Fatores aliados à baixa capacidade de retenção de umidade, intensa lixiviação, considerável susceptibilidade à erosão e granulometria com teores de areia em torno de $90 \%$ também são identificados.

\subsubsection{Aspectos Climáticos}

De acordo com Passos (1997), SEPLAN/MT (2011) e Tarifa (2011) na área onde esta compreendida a Bacia Hidrográfica do rio Cabaçal ocorrem apenas duas estações climáticas. Apesar dos elevados índices pluviométricos registrados para a região, pode se afirmar que a concentração ao longo do período que vai de outubro a março e a acentuada redução que vai de abril a setembro, tem reflexos negativos sobre a dinâmica da paisagem e, por isso mesmo, sobre as condições de forte insolação e elevada temperaturas que se mantém praticamente idênticas à aquelas da estação chuvosa e quente.

A área de estudo esta inserida na unidade climática segundo a classificação de Koppen do tipo AW tropical úmido, com estações de estiagem que podem durar cinco meses e a chuvosa sete meses, com temperatura média do mês mais frio em $18^{\circ} \mathrm{C}$ e a média da temperatura mais quente em torno de $25^{\circ} \mathrm{C}$. 
Quanto ao balanço hídrico, para Bittencout Rosa et al. (1994) a pluviometria média regional é de $1500 \mathrm{~mm}$, com máximo mensal de $140 \mathrm{~mm}$ a $300 \mathrm{~mm}$ aproximadamente, e um mínimo de $20 \mathrm{~mm}$ a $50 \mathrm{~mm}$ durante a estação seca.

A estação chuvosa tem início em setembro e se estende até abril e os meses de dezembro a março correspondem ao verão, sendo caracterizados por um aumento acentuado nas precipitações, já que $80 \%$ das chuvas caem nesse período. A umidade relativa do ar varia na época das grandes precipitações, podendo atingir $70 \%$, enquanto que na estação seca ela é de aproximadamente $50 \%$. A estação seca é caracterizada por um calor intenso, onde as chuvas são escassas e podem precipitar quando existe uma queda acentuada de temperatura, e nessa estação seca a temperatura pode oscilar entre $36^{\circ}$ a $40^{\circ} \mathrm{C}$ (AVELINO 2006; SEPLAN, 2011).

\subsubsection{Aspectos Vegetacionais}

A região onde se localiza a bacia do córrego Peraputanga está situada em contato com dois biomas: Cerrado e Amazônia, nesses domínios são encontradas unidades de paisagem: como cerrado, campo cerrado, campo sujo, campo limpo, cerradão, floresta associada ao Planalto dos Parecis e Formações Secundárias e áreas de usos antrópicos (AMARAL et al, 1982; SEPLAN, 2011).

O projeto RADAMBRASIL (1982) mapeou nove classes de cobertura vegetal natural para a região: Savana, Savana Arbóreo Densa, Savana Arbóreo Aberta sem Floresta de Galeria, Savana Parque com Floresta de Galeria, Floresta Estacional Semidecidual, Floresta Aluvial Dossel Emergente, Floresta Submontana Dossel Emergente, Floresta Estacional Decidual, Floresta Submontana e áreas de Tensão Ecológica.

\subsection{Materiais e métodos}

Inicialmente fez-se a delimitação, mapeamento e localização da área, utilizando um equipamento denominado de GPS (Global Position System), bem como o estaqueamento do local da erosão (voçoroca) com o objetivo de monitorar e registrar o seu avanço, em termos espaciais e temporais, através de medidas, obedecendo sempre um calendário de datas previstas para aferições de largura, comprimento e profundidade; estudos cartográficos para caracterização da área. Os dados pedológicos foram extraídos do RADAMBRASIL (1982).

O mapeamento da evolução desse processo erosivo foi feito a partir da metodologia proposta por Cunha e Guerra (2002), com implantação de estacas de madeira nas bordas da erosão e, aferidas paulatinamente com uma trena (fita métrica), obedecendo sempre a um calendário de datas previstas para visitas na estação seca e na estação chuvosa, conforme necessidade de acompanhamento da evolução das erosões e eventos extremos (chuvas fortes ou secas prolongadas). Durante o período 
desta pesquisa (2014 a 2016), possibilitou obter com exatidão as medidas da evolução desta voçoroca, tanto no período de estiagem como do período chuvoso

\section{RESULTADOS E DISCUSSÕES}

\subsection{Fatores extrínsecos ocasionais - cobertura vegetal e manejo do solo}

Nas imediações da área de estudo, como também no entorno da mesma, ficou evidente a falta de vegetação natural devido desmatamento para implantação de pastagem para criação de gado com gramíneas do gênero brachiária. Registra-se também que o desmatamento foi realizado para a construção da estrada que liga o município de Reserva do Cabaçal ao município de Salto do Céu, causando a aparecimento de erosões e consequentemente o assoreamento de vários córregos e rios da região.

A retirada da cobertura vegetal da área para a formação de pastagem e também para a construção da estrada associada ao solo frágil e a declividade da região favoreceram o rápido crescimento das erosões.

Outro fator que foi observado no local da voçoroca é o que foi enfatizado por Castro Júnior (2002), que a causa da erosão vai além dos desmatamentos, atribui-se também aos processos erosivos a concentração de águas nas linhas de cercas, porque quando se constrói uma cerca, é necessário perfurar a superfície do solo para colocação de moirões e estacas, que funcionará também como um portal de entradas de águas para o interior do solo e, devido à elevada energia das águas, concentrada nestes locais em períodos chuvosos, provoca uma ação extremamente erosiva e intensa, cujo resultado é a abertura de grandes sulcos, como é caso dessa voçoroca na sub-bacia do córrego Peraputanga, que já percorreu mais de 250 metros próximos das linhas de cercas e, com projeções de percorrer esta mesma direção até ao topo da vertente.

\subsection{Fatores intrínsecos topográficos - declividade e comprimento de rampa}

Nessa pesquisa registra-se que da cabeceira da erosão até 20 metros afastada ela não apresenta tanta atividade de aceleração pelo fato de a declividade dela ainda ser pequena, entretanto com o aumento da declividade aumenta a profundidade e a largura da erosão ocasionada pela força da água.

\subsubsection{Propriedades do Solo}

De acordo com SEPLAN (2011) foi encontrado um índice de 48,35\% de teores de areia, entretanto na região em estudo observou-se que esse teor de areia pode atingir $90 \%$, que ainda sim tornam os solos 


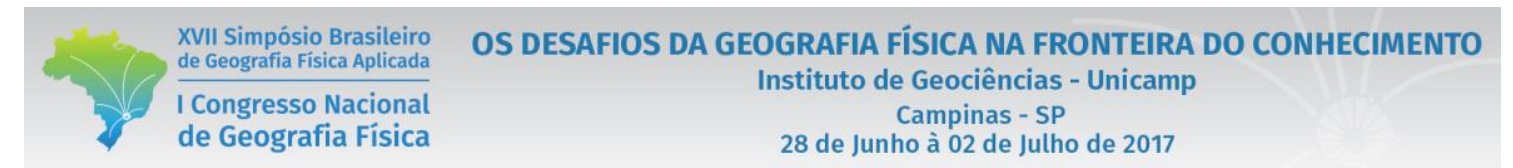

praticamente inviáveis para o uso agrícola, sendo a sua utilização restrita à pastagem em regime extensivo com aproveitamento das espécies vegetais nativas predominantemente.

É possível observar na área de erosão do córrego Peraputanga pontos de friabilidade do solo, devido ao alto teor de areia, baixa percentagem de matéria orgânica, como também de argila; estes são elementos cimentantes que, consequentemente dão ao solo maior resistência aos efeitos das intempéries (erodibilidade); a água inicia um processo de fluidificação do solo em subsuperfície.

\subsection{Monitoramento da Erosão}

O monitoramento da voçoroca, iniciou-se no mês de novembro de 2014 durante uma aula campo da disciplina de geomorfologia II estendendo-se até o mês de março de 2016, compreendendo um período de 16 meses, com objetivo de determinar o grau de desenvolvimento deste fenômeno erosivo, nos períodos de estiagem como também na estação chuvosa.

A voçoroca foi divida em três partes utilizadas para efeito de medidas subdividas em pontos referenciais o ponto I (cabeceira), ponto II (região mediana) e ponto III (final da erosão). Com esses resultados foi possível correlacionar a maior ou menor ocorrência das marcas erosivas, mapeadas e aferidas durante esta pesquisa.

Para realização desta pesquisa, tirou-se as medidas iniciais da referida erosão no mês de novembro de 2014, onde colocado estacas a 1,50 metros do início da erosão. Isso tanto na cabeceira, quanto nas laterais do meio e no fim dela. Os dados de mensuração estão expostos na tabela 1.

Tabela 1: Dados da mensuração da cabeceira da erosão na sub-bacia do Peraputanga.

\begin{tabular}{ccccccc}
\hline DATAS & L.E.E. & D.E.I.E. & L.D. & D.L.D.E. & L.E. & D.L.E.E \\
\hline NOV/2014 & $6,50 \mathrm{M}$ & $1,50 \mathrm{M}$ & $2,91 \mathrm{M}$ & $1,50 \mathrm{M}$ & $2,72 \mathrm{M}$ & $1,50 \mathrm{M}$ \\
FEV/2015 & $6,50 \mathrm{M}$ & $1,34 \mathrm{M}$ & $2,88 \mathrm{M}$ & $1,41 \mathrm{M}$ & $2,64 \mathrm{M}$ & $1,43 \mathrm{M}$ \\
ABR/2015 & $6,50 \mathrm{M}$ & $1,21 \mathrm{M}$ & $2,82 \mathrm{M}$ & $1,35 \mathrm{M}$ & $2,59 \mathrm{M}$ & $1,34 \mathrm{M}$ \\
OUT/2015 & $6,50 \mathrm{M}$ & $1,16 \mathrm{M}$ & $2,69 \mathrm{M}$ & $1,27 \mathrm{M}$ & $2,48 \mathrm{M}$ & $1,23 \mathrm{M}$ \\
MAR/2016 & $6,50 \mathrm{M}$ & $1,02 \mathrm{M}$ & $2,56 \mathrm{M}$ & $1,12 \mathrm{M}$ & $2,39 \mathrm{M}$ & $1,08 \mathrm{M}$ \\
\hline
\end{tabular}

L.E.E = Largura de Estaca a Estaca D.E.I.E = Distância da Estaca ao Inicio da Erosão

$\begin{array}{ll}\text { L.D. }=\text { Lado Direito } & \text { D.L.D.E }=\text { Distancia do Lado Direito a Estaca }\end{array}$

L.E. $=$ Lado Esquerdo $\quad$ D.L.E.E. $=$ Distância do Lado Esquerdo a Estaca

Na cabeceira da erosão, conforme exposto na tabela 1, os dados mostram que do início ao fim da pesquisa ocorreu avanço na referida erosão, com destaque para os períodos com maior concentração e volume de pluviosidade, sendo $0,48 \mathrm{~m}$ de evolução da erosão da primeira estaca ao início da área erodida; $0,35 \mathrm{~m}$ de distância da estaca a base da erosão do lado direito; $0,38 \mathrm{~m}$ da estaca ao topo da 
erosão do lado direito; 0,33 $\mathrm{m}$ do da estaca a base da erosão do lado esquerdo; 0,42 $\mathrm{m}$ da estaca ao topo da erosão do lado esquerdo, isso durante os 16 meses de pesquisa.

Tabela 2: Dados da mensuração do meio da erosão na sub-bacia do Peraputanga.

\begin{tabular}{llllll}
\hline DATAS & L.E.E. & L.D. & D.L.D.E. & L.E. & D.L.E.E. \\
\hline NOV/2014 & $17,70 \mathrm{M}$ & $13,89 \mathrm{M}$ & $1,50 \mathrm{M}$ & $5,04 \mathrm{M}$ & $1,50 \mathrm{M}$ \\
FEV/2015 & $17,70 \mathrm{M}$ & $13,76 \mathrm{M}$ & $1,42 \mathrm{M}$ & $4,93 \mathrm{M}$ & $1,44 \mathrm{M}$ \\
ABR/2015 & $17,70 \mathrm{M}$ & $13,60 \mathrm{M}$ & $1,36 \mathrm{M}$ & $4,87 \mathrm{M}$ & $1,38 \mathrm{M}$ \\
OUT/2015 & $17,70 \mathrm{M}$ & $13,48 \mathrm{M}$ & $1,20 \mathrm{M}$ & $4,76 \mathrm{M}$ & $1,32 \mathrm{M}$ \\
MAR/2016 & $17,70 \mathrm{M}$ & $13,36 \mathrm{M}$ & $1,11 \mathrm{M}$ & $4,61 \mathrm{M}$ & $1,19 \mathrm{M}$ \\
\hline
\end{tabular}

Quando analisado os dados contidos na tabela 2, observa-se que a mensuração do meio da erosão da sub-bacia do Peraputanga, apresenta uma constante evolução na área, que teve um avanço de 0,53 m no lado direito da mesma isso quando medido da estaca a base da erosão e 0,39 m quando medido da estaca ao topo da erosão do mesmo lado; do lado esquerdo da mesma erosão o avanço 0,43 m quando medido da estaca a base da erosão e $0,31 \mathrm{~m}$ da estaca ao topo da erosão do mesmo lado.

Tabela 3: Dados da mensuração do fim da erosão na sub-bacia do Peraputanga.

\begin{tabular}{llllll}
\hline DATAS & L.E.E. & L.D. & D.L.D.E. & L.E. & D.L.E.E. \\
\hline NOV/2014 & $19,43 \mathrm{M}$ & $6,54 \mathrm{M}$ & $1,50 \mathrm{M}$ & $14,86 \mathrm{M}$ & $1,50 \mathrm{M}$ \\
FEV/2015 & $19,43 \mathrm{M}$ & $6,47 \mathrm{M}$ & $1,46 \mathrm{M}$ & $14,78 \mathrm{M}$ & $1,39 \mathrm{M}$ \\
ABR/2015 & $19,43 \mathrm{M}$ & $6,40 \mathrm{M}$ & $1,35 \mathrm{M}$ & $14,60 \mathrm{M}$ & $1,36 \mathrm{M}$ \\
OUT/2015 & $19,43 \mathrm{M}$ & $6,35 \mathrm{M}$ & $1,23 \mathrm{M}$ & $14,22 \mathrm{M}$ & $1,23 \mathrm{M}$ \\
MA016 & $19,43 \mathrm{M}$ & $6,22 \mathrm{M}$ & $1,09 \mathrm{M}$ & $14,07 \mathrm{M}$ & $1,16 \mathrm{M}$ \\
\hline
\end{tabular}

A tabela 3 representa a mensuração do fim da erosão da sub-bacia do Peraputanga, traz em suas informações uma grande evolução na área da erosão, onde do lado direito da mesma teve um avanço de $0,32 \mathrm{~m}$ quando medido da estaca a base da erosão e de $0,41 \mathrm{~m}$ da estaca ao topo da mesa do mesmo lado; do lado esquerdo o avanço foi de $0,79 \mathrm{~m}$ quando medido da estaca a base e $0,34 \mathrm{~m}$ da estaca ao topo da erosão. Nota-se que na área do fim da erosão o desgaste do lado esquerdo da erosão foi mais que o dobro do lado direito, devido a declividade do terreno, e também que essa área evoluiu mais que as seções do meio e também cabeceira.

Ao confrontar as mensurações aferidas desde o início ate o término, constatou-se que a progressão desta voçoroca ocorreu com maior velocidade nos períodos de maior concentração pluviométrica.

No que se refere a fragilidade ambiental da área, levando-se em consideração o tipo de solo, declividade e pluviosidade, a área pode ser enquadrada na Classe de Fragilidade Muito Alta, onde 


$\begin{aligned} & \text { XVII Simpósio Brasileiro } \\ & \text { de Geografia Fisica Aplicada }\end{aligned}$
$\begin{aligned} & \text { I Congresso Nacional } \\ & \text { de Geografia Física }\end{aligned}$

observa-se a ocorrência de solos frágeis, declividade de média a alta com maior grau de influência nos processos erosivos e maior proximidade dos recursos hídricos.

No conceito de Tricart (1977), a área pesquisada, enquadra-se em Unidades Ecodinâmicas Instáveis, uma vez que, a intervenção antrópica acelerou os processos erosivos, pois modificaram intensamente os ambientes naturais através do desmatamento e práticas agropecuárias mal planejada.

\section{4 - CONSIDERAÇÕES FINAIS}

As erosões em Reserva do Cabaçal, são causadas pela fragilidade e instabilidade do solo, que apresenta em sua composição mineralógica grande quantidade de areia, favorecendo a formação de sulcos e ravinas ocasionada pelas chuvas no verão e pelo vento no inverno.

Embora esta pesquisa tenha sido executada em intervalos de três (3) meses por 16 meses, prazo razoavelmente pequeno para fazer todas as análises ambientais necessárias, constatou-se que o processo erosivo foi influenciado por vários fatores: desnível altimétrico, sem nenhuma barreira para quebra de velocidade do escoamento superficial (runoff); influência da perfuração do solo para construção de cercas e estradas que funcionam como um portal de entrada de águas para o subsolo, contribuindo para a fluidificação dos materiais em subsuperfície; corredor sem vegetação protetora ao longo da voçoroca; falta de vegetação natural; pastoreio excessivo e, de acordo com os resultados das análises laboratoriais das amostras de solo, o solo foi considerado frágil.

Assim, acredita-se que a verdadeira causa de erosão acelerada do solo, está na maior ou menor fragilidade dos solos perante o trabalho das águas combinadas com fatores naturais e manejo irregular.

\section{REFERÊNCIAS BIBLIOGRÁFICAS}

ALMEIDA. F. F. M.; DERZE, G. R.; VINHA, C. A. G. Mapa Geológico do Brasil. Rio de Janeiro . DNPM, escala 1: 5.000.000, 1971.

AMARAL, D. L.; FONZAR, B. C.; OLIVEIRA FILHO, L. C. Vegetação. Folha SD. 21/Cuiabá. BRASIL/M.M.E. Rio de Janeiro: Projeto RADAMBRASIL, 1982. P. 401-452.

AVELINO, P. H. M. Análise Geo-ambiental Multitemporal para fins de Planejamento Ambiental: um exemplo aplicado à Bacia Hidrográfica do Rio Cabaçal, Mato Grosso - Brasil. 2006. 323 f. Tese (Doutorado em Geografia) - Universidade Federal do Rio de Janeiro, Rio de Janeiro.

BARROS, A. M.; SILVA, R. H. da; CARDOSO, O. R. F. A.; FREIRE, F. A.; SOUZA JÚNIOR, J. J. de; RIVETTI, M.; LUZ, D. S. da; PALMEIRA, R. C. de; TASSINARI, C. C. G. Geologia. Folha SD 21 - Cuiabá. Brasil, MME, Projeto Radambrasil (Levantamento dos Recursos Naturais, 26), p. 25-192, Rio de Janeiro, 1982.

BITTENCOURT ROSA, ; ARRUDA. M. W. de; GARCIA NETO, L. da R.; MENEZES LIMA, P. R. Uma Caracterização Analítica Geomorfológica da Região entre Salto do Céu - Cristianópolis, MT, como uma Contribuição ao seu Planejamento de Uso da Terra. In: Simpósio de Geologia da Amazônia, 4, Belém, PA. Anais da Sociedade Brasileira de Geologia , v.1, p.58-60, Belém, PA, 1994.

CASSETI, V. Ambiente e apropriação do relevo. São Paulo: Contexto, (Coleção ensaios). 1991, 147 p. 
CASTRO JUNIOR, P. R. de. Erosão dos Solos. Cuiabá: Instituto Pró-Natura, 2002, 30 p.

CRISTO, S. S. V. Análise de susceptibilidade a riscos naturais relacionados às enchentes e deslizamentos do setor leste da bacia hidrográfica do rio Itacorubi, Florianópolis - SC. 211 f. Dissertação (Mestrado) Curso de Pós-Graduação em Geografia, Universidade Federal de Santa Catarina, Florianópolis, 2002.

CUNHA, S. B. da; GUERRA, A. J. T. Geomorfologia: exercícios, técnica e aplicações/ Sandra Baptista da Cunha e Antonio José Teixeira Guerra (orgs.) - 2. ed.-Rio de Janeiro; Bertrand Brasil, 2002, 345 p.

FIGUEIREDO, A. J.; OLIVATTI, O. Projeto alto Guaporé, relatório final.Goiânia, D.N.P.M - CPRM, 11 v. (relatório de arquivo técnico da DGM), 1974.

GUERRA, A. J. T.; JORGE, M. do C. O. Processos erosivos e recuperação de áreas degradadas/Antonio José Teixeira Guerra, Maria do Carmo Oliveira Jorge, organizadores. São Paulo: Oficina de textos, 2013.

MOROZ-CACCIA GOUVEIA, I. C. Da originalidade do sítio urbano de São Paulo às formas antrópicas: aplicação da abordagem da geomorfologia antropogênica na Bacia Hidrográfica do Rio Tamanduateí, na Região Metropolitana de São Paulo, 363 f. Tese (Doutorado) - Departamento de Geografia, Faculdade de Filosofia, Letras e Ciências Humanas, Universidade de São Paulo, São Paulo, 2010.

NIR, D. Man, a geomorphologycal agent: na introdution to anthropic geomorphology. Jerusalém: Ketem Pub. House 1983. 184 p.

PASSOS, M. M. dos P. Teledetecção Aplicada ao Estudo da Paisagem: Sudoeste de Mato Grosso. Presidente Prudente: UNESP, 1997. (tese de Pós-Doutorado).

PROJETO RADAMBRASIL. Levantamentos de Recursos Naturais. Ministério das Minas e Energia, Secretaria Geral. Volumes 26 e 27. Rio de Janeiro, 1982

ROSS, J. L. S. Análise Empírica da Fragilidade dos Ambientes Naturais e Antropizados. Revista do Departamento de Geografia/FFLCH/USP, n.8, p.63-73, 1994.

SALOMÃO, F. X. T. Processos erosivos lineares em Baurú (SP): regionalização cartográfica aplicada ao controle preventivo urbano e rural. São Paulo, 200 p. (Tese de Doutoramento FFLCH - USP. Departamento de Geografia), 1994.

SEPLAN - Secretaria de Estado de Planejamento e Coordenação Geral. Ligia Camargo (Org). Atlas de Mato Grosso: abordagem socieconomico-ecológica. Cuiabá: Entrelinhas, 2011.

SOUZA E. P.; HILDRADE, P R. Contribuição ao Estudo da Geologia do Grupo Aguapeí, Oeste de Mato Grosso. In: Congresso Brasileiro de Geologia. Anais vol. 2, págs. 813-820. Sociedade Brasileira de Geologia, 1980.

TARIFA, J. R. Mato Grosso: Clima: Análise e Representação Cartográfica. Cuiabá-MT Entrelinhas, 2011.

TRICART, J. Ecodinâmica. Rio de Janeiro: FIBGE, Secretaria de Planejamento da Presidência da República, 1977. 97p.

WILD, A. Soils and the environment: na introduction. Cambridge: Cambridge University Press, 1993. 287 p. 